\title{
Comparative biomechanical testing of customized three-dimensional printing acetabular-wing plates for complex acetabular fractures
}

\author{
Xiangyuan Wen ${ }^{1, B, D-F}$, Hai Huang ${ }^{1, B, F}$, Canbin Wang ${ }^{1, C, F}$, Jianghui Dong ${ }^{2, D-F}$, \\ Xuezhi Lin ${ }^{1, C, F}$, Fuming Huang ${ }^{1, C, F}$, Hua Wang ${ }^{1, A, F}$, Liping Wang ${ }^{2, D-F}$, Shicai Fan ${ }^{1, A, F}$ \\ ${ }^{1}$ The Third Affiliated Hospital, Southern Medical University, Guangzhou, China \\ 2 UniSA Clinical \& Health Sciences, UniSA Cancer Research Institute, University of South Australia, Adelaide, Australia \\ A - research concept and design; $B$ - collection and/or assembly of data; $C$ - data analysis and interpretation; \\ $\mathrm{D}$ - writing the article; $\mathrm{E}$ - critical revision of the article; $\mathrm{F}$ - final approval of the article
}

Address for correspondence

Shicai Fan

E-mail: fanscyi@sohu.com

\section{Funding sources}

This study was funded by the Special Program of Guangdong Frontier and Key Technological Innovation (No. 2015B010125006), the National Natural Science Foundation of China (No. 81772428) and the Australian National Health and Medical Research Council (NHMRC) Fellowship (№. 1158402).

Conflict of interest None declared

Received on September 24, 2019 Reviewed on 0ctober 15, 2019 Accepted on January 21,2020

Published online on April 29, 2020

\begin{abstract}
Background. Three-dimensional (3D) printing of an acetabular wing-plate is a new minimally invasive surgical technique for complex acetabular fractures.

Objectives. To investigate the biomechanical stability of 3D printing acetabular wing-plates. The results were compared with 2 conventional fixation systems.

Material and methods. Eighteen fresh frozen cadaveric pelvises with both column fractures were randomly divided to 3 groups: A - iliosciatic plates fixation system; B $-3 D$ printing plates; $C-2$ parallel reconstruction plates fixation system. These constructions were loaded onto a biomechanical testing machine. Longitudinal displacement and stiffness values of the constructs were measured to estimate their stability.

Results. When the load force reached $700 \mathrm{~N}$, Group A was superior to Group B in the longitudinal displacement of point $1(p>0.05)$. The longitudinal displacement of point 2 showed no significant differences among Groups $A, B$ and $C$, and the displacement of the fracture line over point 3 showed no significant differences between Groups A and B ( $p>0.05$ ). The axial stiffness of Groups A, B and C were $122.4800 \pm 8.8480 \mathrm{~N} / \mathrm{mm}$, $168.4830 \pm 14.8091 \mathrm{~N} / \mathrm{mm}$ and $83.1300 \pm 3.8091 \mathrm{~N} / \mathrm{mm}$, respectively. Group B was significantly stiffer than $A$ and $C(p<0.05)$. Loads at failure of internal fixation were $1378.83 \pm 34.383 \mathrm{~N}, 1516.83 \pm 30.896 \mathrm{~N}$ and $1351.00 \pm 26.046 \mathrm{~N}$ for Groups A, B and C, respectively. Group B was significantly superior to Groups A and C $(p>0.05)$
\end{abstract}

Conclusions. Customized 3D printing acetabular-wing plates provide stability for acetabular fractures compared to intraspecific buttressing fixation.

Key words: internal fixation, three-dimensional printing, acetabular fracture, biomechanical tests

Cite as

Wen X, Huang H, Wang C, et al. Comparative biomechanical testing of customized three-dimensional printing acetabularwing plates for complex acetabular fractures. Adv Clin Exp Med. 2020;29(4):459-468. doi:10.17219/acem/116749

DOI

10.17219/acem/116749

Copyright

Copyright by Author(s)

This is an article distributed under the terms of the

Creative Commons Attribution 3.0 Unported (CC BY 3.0)

(https://creativecommons.org/licenses/by/3.0/) 


\section{Introduction}

Acetabular fractures are complex injuries and associated with significant morbidity and mortality. ${ }^{1,2}$ These injuries frequently occur in high-energy traumas and can lead to posttraumatic arthritis or disabilities. ${ }^{3}$ Due to the prolongation of human life span, coupled with the rise in the occurrence of osteoporosis, the incidence of acetabular fractures has distinctly increased. ${ }^{4}$ Culemann et al. found that the force required to displace an osteoporotic cadaveric fracture is significantly small. ${ }^{5}$ Therefore, it is necessary to find an effective treatment method for complex fractures of the acetabulum.

The medial boundary of the acetabulum is formed by the quadrilateral plate, and as a relatively thin bony structure, this area is more prone to fractures than the weight bearing areas. Fractures also occur under lower forces ${ }^{6}$ and appear as both-column, anterior column, and posterior hemi-transverse $\mathrm{T}$-shaped fractures or posterior column and combined transverse fractures, often accompanied by quadrilateral plate fractures with medial displacement. ${ }^{7}$

In a previous study, Letournel confirmed that conservative fracture treatment was not satisfactory. ${ }^{8}$ Open reduction and internal fixation method are currently considered standard treatment for displaced acetabular fractures involving weight-bearing domains and fractures of the intraarticular fragment. Inadequate reduction and stabilization of quadrilateral plate fractures leads to incongruous joints and posttraumatic arthritis. ${ }^{9}$ The classic fixation technique is the ilioinguinal approach, ${ }^{10}$ which involves placing reconstruction plates at the pelvic margin and extending the screw distally to the posterior column. Although the current treatment protocol using multiple elongated or ace-shaped reconstruction plates and lag screws for the stabilization of the pelvic ring and hip joint has been shown to effectively reduce mortality, these fixators cause a high frequency of new morbidities. ${ }^{11}$ Recently, studies have confirmed that early postoperative rehabilitation training is beneficial to joint function recovery; therefore, a rigid fixation implant for acetabular fossa and pelvic rings that allows early mobilization is important for these injuries. ${ }^{12}$ In a biomechanical study, Mehin et al. showed that locking plates may improve the management of acetabular fractures by eliminating the need for an interfragmentary lag screw, and they may be helpful in revision hip arthroplasty in patients with pelvic discontinuity. ${ }^{13}$ However, their study only loaded $250 \mathrm{~N}$ as an axial force, which did not meet the requirement of physiological weight-bearing conditions. These fixators were associated with multiple complications including pin site infection and fixator loosening. Besides the conventional reconstruction, bone plate mostly depends on the structure of the acetabulum and needs to be pre-contoured to bone surface before fixation. ${ }^{14}$ Utilizing reconstruction plates and more screws to maintain reduction during surgery is a potentially serious postoperative complication that may lead to post-traumatic osteoarthritis. In recent years, 3D printing technology has been widely used in orthopedics for internal implant manufacturing. ${ }^{14-16}$ It allows an individual plate to be designed for particular patients according to the fracture line and the surface of the acetabulum. A wing-shaped plate for both-column acetabulum fractures was designed (Fig. 1), and the pre-contoured shape, extended fix range, the oval screw hole and the angular stability were used to design the wing-shaped plate. However, prior to widespread adoption of these new concepts, a critical step in the systematic investigation of any new fixation strategy involves comparative biomechanical efficacy in a cadaveric model.

The aim of this study was to gather the evidence regarding the biomechanical stability of 3D printing acetabularwing plates relative to 2 conventional fixation systems. Firstly, an effective method to produce personalized acetabular fracture plates was developed. Then, the displacement of the fracture line was measured and analyzed by applying stress on broken cadaver pelvises after internal fixation. Lastly, the stability of the 3D printed bone plate was evaluated by comparing the displacement of fracture line and stiffness with that of the traditional internal fixations.
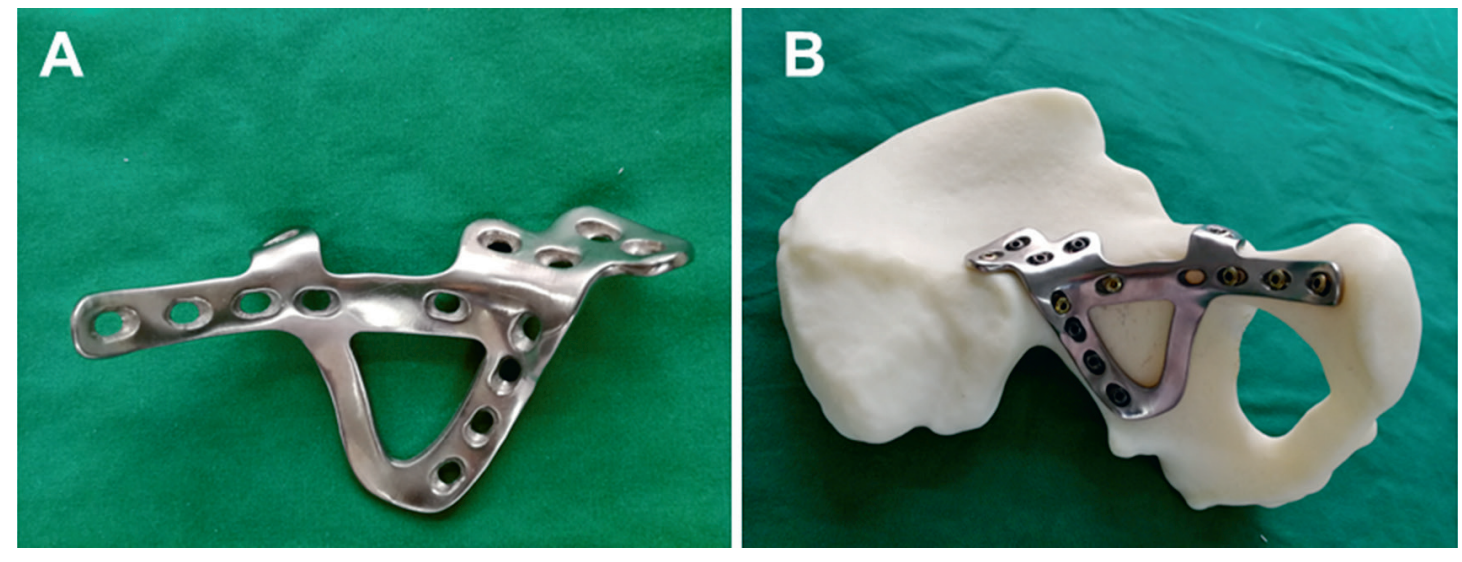

Fig. 1. 3D customized wing plates

A - 3D customized wing plates for use in complex acetabular fractures; B - preoperative design of 3D customized wing plates. 


\section{Material and methods}

\section{Specimen preparation}

Nine male fresh frozen cadaveric pelvises were provided by the Department of Anatomy of the Southern Medical University in Guangzhou, China. Soft tissue and ligaments were removed from the surface, and the joint of the sacroiliac and the pubic bone were sawed. Eighteen hemipelvis samples were obtained after trimming. All donors or their next of kin provided written informed consent for the study. All specimens were visually and radiographically examined for evidence of abnormalities, and the bone mineral density was quantified using dual energy X-ray osteodensitometers prior to dissection. Each specimen revealed no signs of arthritis, malignancy or osteoporosis. We designed the proximal $1 / 3$ of both femurs according to 3D specimen images obtained by using Mimics v. 19.0 (Materialise Software, Leuven, Belgium). Each hemipelvic area had an artificial proximal 1/3 of femurs to match. Each artificial femur was connected with the biomechanical testing machine.
We randomly divided the 18 specimens into 3 fixation groups (Fig. 2). In Group A, iliosciatic plating and 2 lag screws were used. In Group B, we used customized 3D printing acetabular-wing plates and 2 lag screws. In Group $\mathrm{C}$, we used parallel reconstruction plates and 2 lag screws. The fixation experiments were performed in accordance with the relevant regulations and approved by the medical ethics committee of the Third Affiliated Hospital of Southern Medical University in Guangzhou, China.

\section{Fracture models}

A both-column acetabulum fracture was created with a saw according to the Judet-Letournel classification ${ }^{8,17}$ (Fig. 3). The $1^{\text {st }}$ osteotomy line originated from the iliac crest through the quadrilateral surface to the brim of the incisura acetabula (points $\mathrm{a}-\mathrm{b}$ ). The $2^{\text {nd }}$ osteotomy line ran from the ischial spine to the center of the quadrilateral surface (points $\mathrm{c}-\mathrm{d}$ ). The $3^{\text {rd }}$ osteotomy line ran from the linear arcuate to the vertex of the great sciatic notch (points e-f). A fracture of the pubic bone was also created (point g).
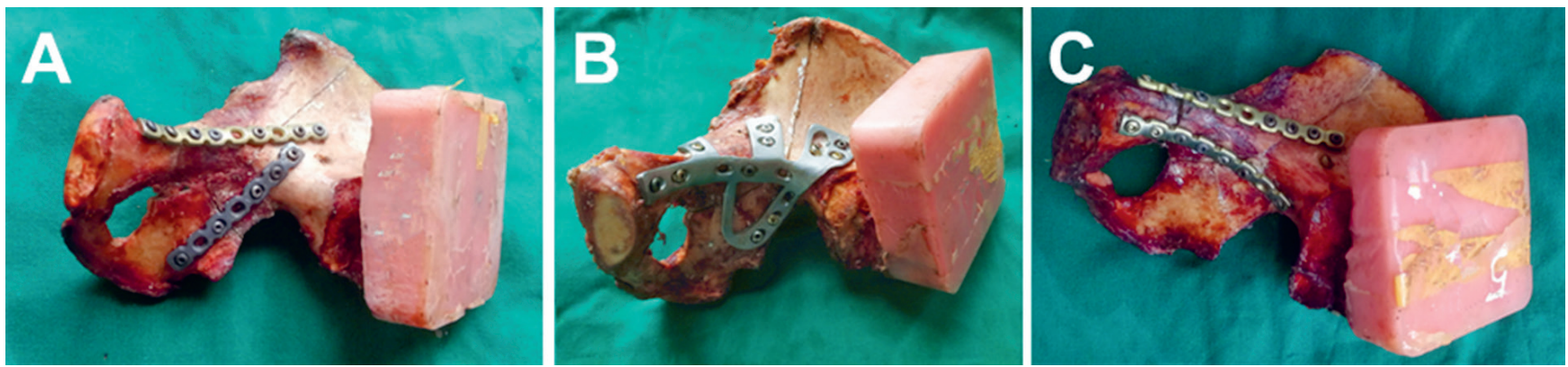

Fig. 2. Groups of different fixation constructs

A - Group A: iliosciatic plates and 2 screws; B - Group B: 3D printing customized bone plates and 2 lag screws; C - Group C: 2 parallel reconstruction plates and 2 lag screws.
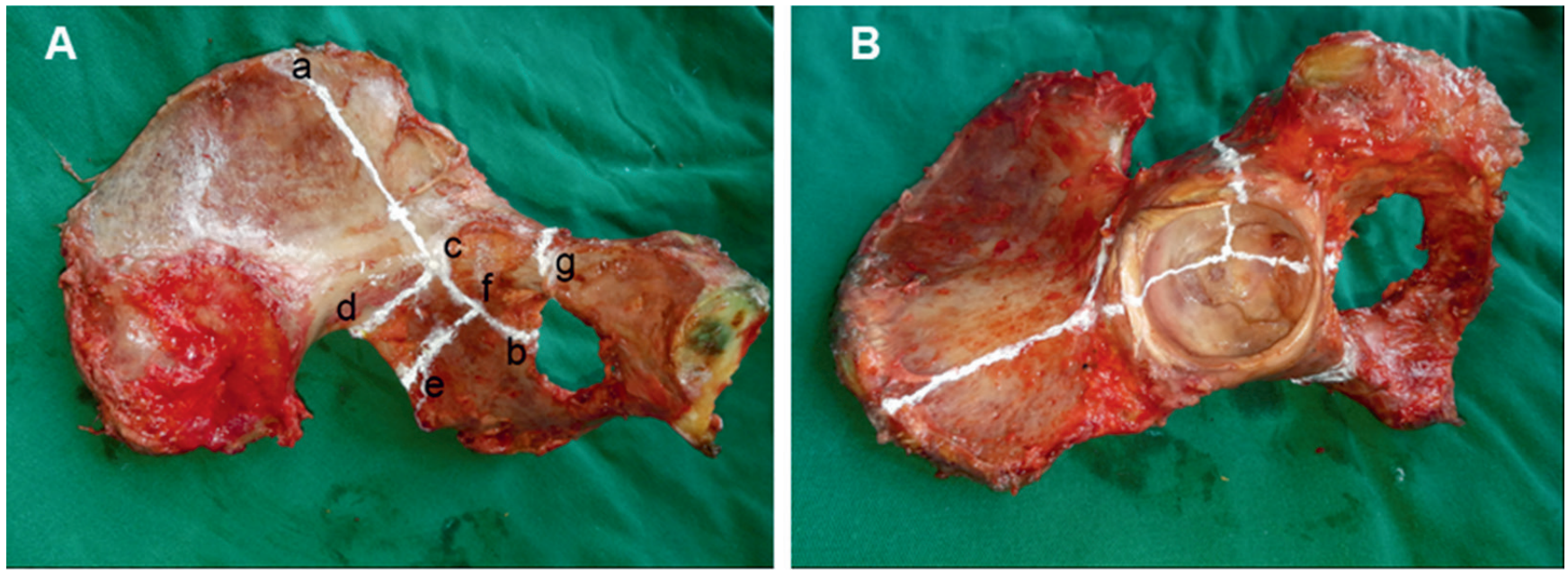

Fig. 3. Complex both-column acetabular fracture

A - the $1^{\text {st }}$ osteotomy line originated from the iliac crest through the quadrilateral surface to the brim of the incisura acetabular (points a-b). The $2^{\text {nd }}$ osteotomy line ran from the ischial spine to the center of the quadrilateral surface (points $c-d$ ). The $3^{\text {rd }}$ osteotomy line ran from the linear arcuate to the vertex of the great sciatic notch (points e-f). A fracture of the pubic bone was also created (point g); B - the dorsal view of specimen with fracture line. 


\section{Design of the customized 3D-printing acetabular-wing plate}

\section{D models of the specimens}

A computed tomography $(\mathrm{CT})$ was performed for each intact specimen, and data was obtained in the Digital Imaging and Communications in Medicine (DICOM) format. The CT data of the pelvis specimens was imported into the Materialise's interactive medical image control system (Mimics v. 19.0) and a 3D model was calculated according to the CT data. All data was stored as binary stereolithography (STL) data (Fig. 4).

\section{Original shape of the customized bone plate}

Binary STL data was imported into Geomagic ${ }^{\circledR}$ Studio v. 12.0 (3D Systems, Rock Hill, USA) and the location of the pelvic fracture line was used as a reference. The graphics of the bone plate was obtained according to the contralateral acetabulum surface morphology, the location and shape of the acetabulum fracture, and the placement of the bone plate area. The bone plate thickness $(3 \mathrm{~mm})$ and fitted the curved surface of the customized $3 \mathrm{D}$ bone plate model were set. The pelvic and bone plate models were derived in the STEP format (Fig. 4).

\section{Fabrication of screw holes of the customized} bone plate

Screw holes were added according to the shape and specifications of the screws. M3.5 compressive screws and
M6.5 pressure screws (generally used for conventional bone plates) were employed (Fig. 4).

\section{Manufacturing the bone plate}

Customized 3D printing acetabular-wing plates were manufactured using metal additive manufacturing technology. Processed data was imported into a self-developed DiMetal-100 metal 3D printing device. The final step involved heat and surface treatment. Samples were heated to $820^{\circ} \mathrm{C}$ for $3 \mathrm{~h}$, incubated for $2 \mathrm{~h}$, and cooled to $450^{\circ} \mathrm{C}$ in a furnace. The furnace was then opened and the samples were air-cooled. Surface treatment procedures included roll casting, oil cleaning, acid pickling, polishing, anodizing, cleaning, and disinfection. ${ }^{18}$ The properties of the customized bone plate were then evaluated (Fig. 4).

\section{Biomechanical testing}

Specimens were fixed in the stance position as previously described by Gillispie et al. ${ }^{19}$ According to the single inverted foot standing method, specimens were fixed using denture-based polymers. At the base of the biomechanical experimental machine (BOSE Corporation, Eden Prairie, USA), specimens were embedded and the upper end of the test machine was connected to the broken ends of the femoral shaft for biomechanical testing. Points 1 , 2 and 3 on each specimen were marked as the displacement measurement points along the fracture line as shown in Fig. 5A. The $100 \mathrm{~N}$ preload was applied on 3 occasions and a $20 \mathrm{~N} / \mathrm{s}$ rate was continually loaded to $700 \mathrm{~N}$. Longitudinal displacement of the fracture was measured using

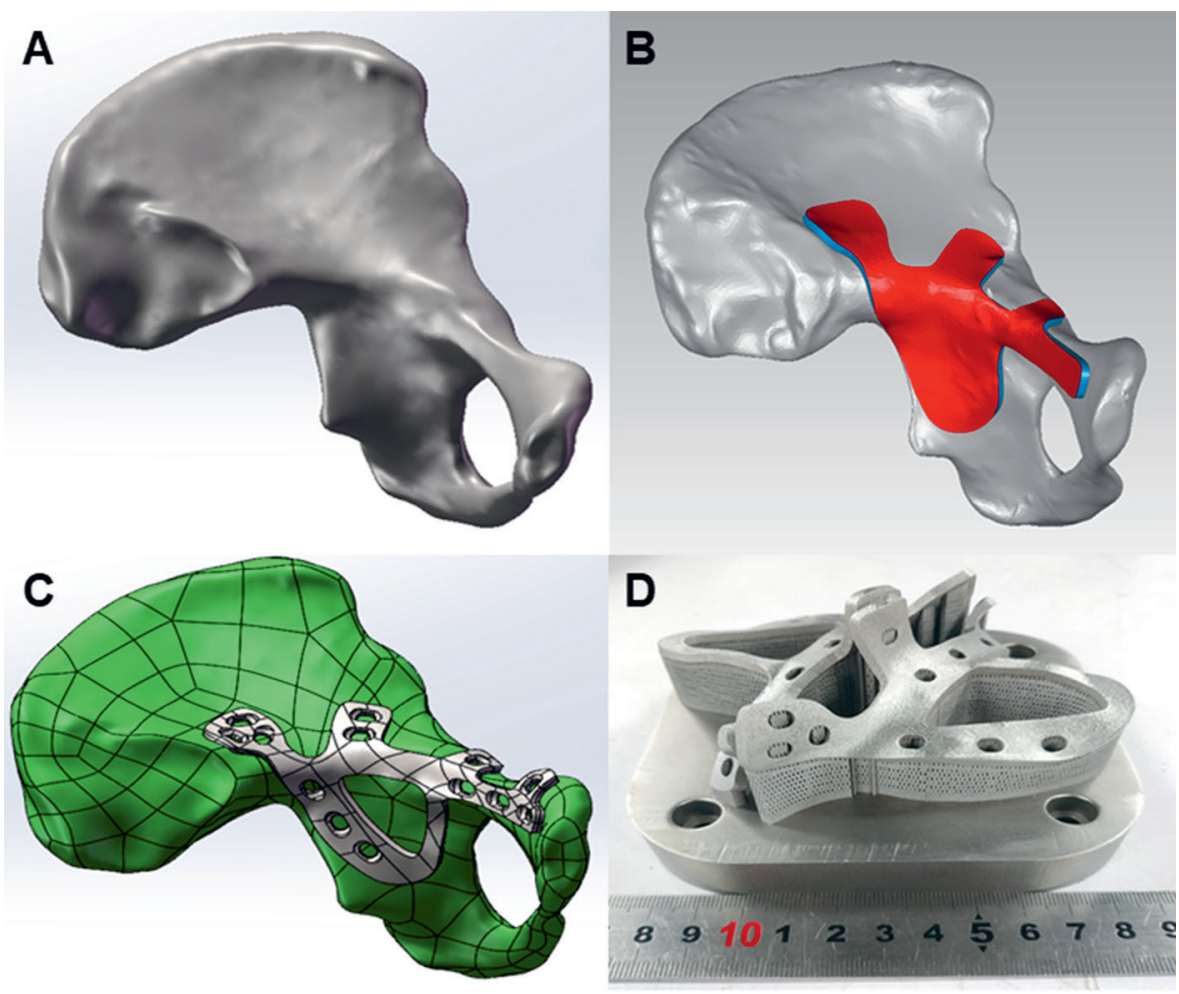

Fig. 4. Design process of 3D customized wing plates

A - 3D model of the specimens;

$B$ - original shape of the customized bone plate; $\mathrm{C}$ - fabrication of screw holes of the customized bone plate D - manufacturing the bone plate. 


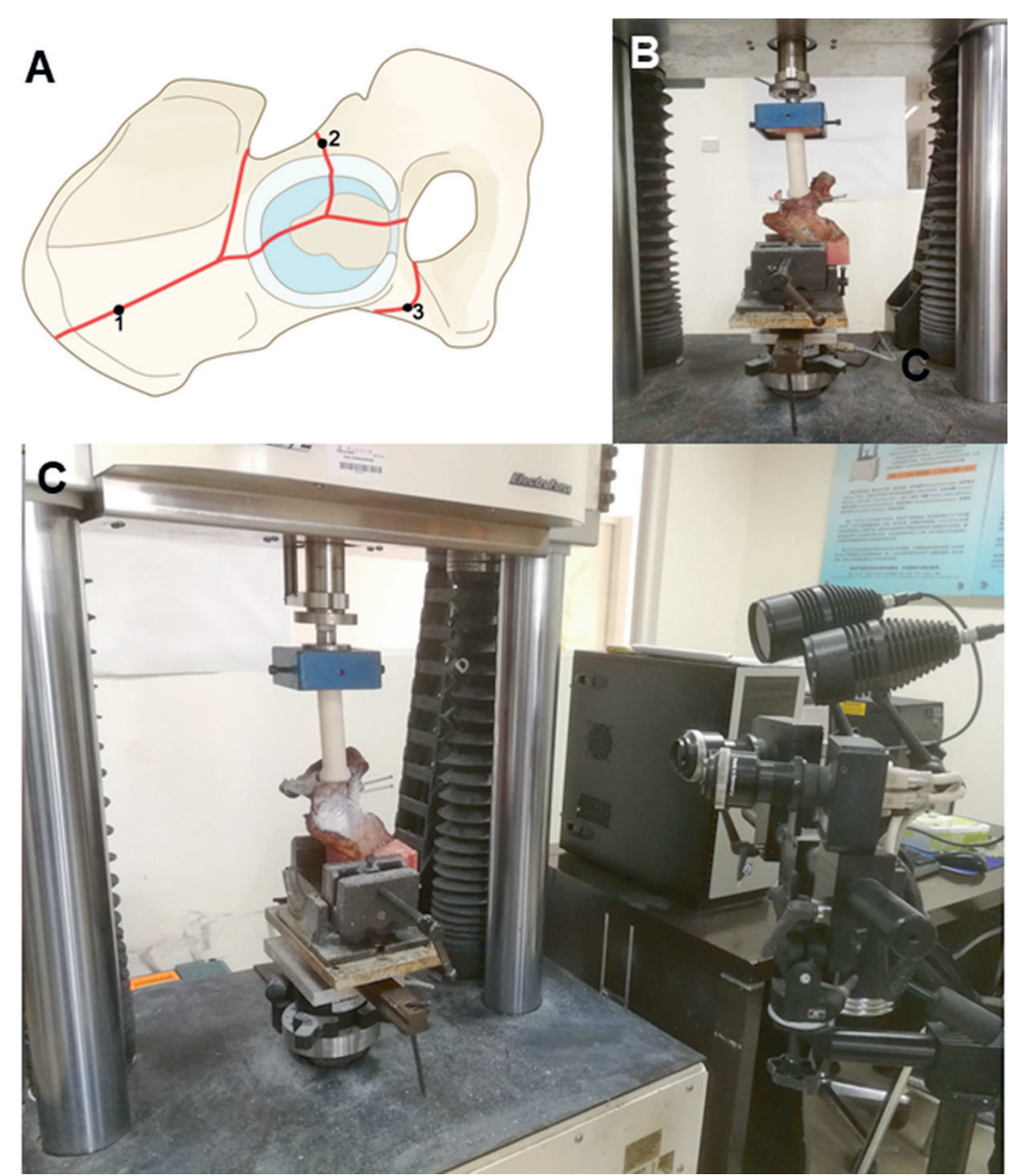

a high-precision grating displacement sensor. Specimens were repeatedly loaded on 6 occasions and mean values were obtained. Stiffness was defined as the slope of the force vs the displacement curve.

\section{Results}

\section{Longitudinal displacement}

The longitudinal displacement of each group of fractures under the same load was used to evaluate the stability
Fig. 5. The load cell and jig used to position the pelvis and femur

A - positions of the displacement at points 1-3 around the pelvis; $\mathrm{B}-\mathrm{C}$ - biomechanical testing. Specimens were fixed in the stance position, fixed using denture-based polymers. Specimens were embedded and the upper end of the test machine was connected to the broken ends of the femoral shaft for biomechanical testing.

of internal fixation. No plates were broken and no screws were pulled out or broken at a force $\leq 700 \mathrm{~N}$. As shown in Table 1 and Fig. 6, the significant difference of fracture displacement was presented when the loading force exceeded $500 \mathrm{~N}$ at point 1 region as well as point 3 . However, no statistical significant displacement was displayed in each group at point 2 region. When the loading force reached $700 \mathrm{~N}$ (the average human body weight), the significant differences were shown between Groups B and A, B and C in the fracture line longitudinal displacement measurement of point 1 region. No significant differences between Group A and C occurred. The performance of Group B was superior to Groups $A$ and $C$. The results of the fracture line longitudinal displacement measurement point 2 showed no significant differences among Groups A, B and C. And the results of the fracture line longitudinal displacement measurement point 3 showed no significant differences between Groups A and B ( $p>0.05)$, both of which were superior to the Group $C$ $(\mathrm{p}<0.05)$ (Fig. 7).

\section{Axial stiffness}

The axial stiffness of the internal fixation is reflected by its ability to resist deformation and maintain joint stability under axial loads. Using the formula: $S=F / \Delta L(S-$ axial stiffness, $\mathrm{F}$ - load, $\Delta \mathrm{L}$ - deformation displacement) the axial stiffness of Groups A, B and C were $122.4800 \pm 8.8480 \mathrm{~N} / \mathrm{mm}$,

Table 1. Mean displacement of different fixations in each point when under pressure

\begin{tabular}{|c|c|c|c|c|c|c|c|c|c|}
\hline \multicolumn{3}{|c|}{ Loading force [N] } & 100 & 200 & 300 & 400 & 500 & 600 & 700 \\
\hline \multirow{9}{*}{$\begin{array}{l}\text { Displacement } \\
{[\mathrm{mm}]}\end{array}$} & \multirow{3}{*}{ point 1} & Group A & $0.10 \pm 0.03$ & $0.21 \pm 0.02$ & $0.32 \pm 0.07$ & $0.45 \pm 0.11$ & $0.66 \pm 0.09$ & $0.87 \pm 0.09$ & $1.09 \pm 0.15$ \\
\hline & & Group B & $0.10 \pm 0.03$ & $0.20 \pm 0.06$ & $0.30 \pm 0.10$ & $0.38 \pm 0.10$ & $0.44 \pm 0.10$ & $0.50 \pm 0.11$ & $0.62 \pm 0.08$ \\
\hline & & Group C & $0.11 \pm 0.03$ & $0.21 \pm 0.03$ & $0.37 \pm 0.07$ & $0.54 \pm 0.13$ & $0.77 \pm 0.12$ & $0.96 \pm 0.18$ & $1.27 \pm 0.10$ \\
\hline & \multirow{3}{*}{ point 2} & Group A & $0.12 \pm 0.03$ & $0.28 \pm 0.05$ & $0.44 \pm 0.08$ & $0.65 \pm 0.12$ & $0.83 \pm 0.10$ & $1.10 \pm 0.14$ & $1.44 \pm 0.09$ \\
\hline & & Group B & $0.10 \pm 0.02$ & $0.21 \pm 0.02$ & $0.35 \pm 0.05$ & $0.56 \pm 0.05$ & $0.75 \pm 0.03$ & $1.01 \pm 0.06$ & $1.24 \pm 0.09$ \\
\hline & & Group C & $0.15 \pm 0.02$ & $0.31 \pm 0.04$ & $0.54 \pm 0.07$ & $0.73 \pm 0.09$ & $0.99 \pm 0.12$ & $1.31 \pm 0.07$ & $1.62 \pm 0.06$ \\
\hline & \multirow{3}{*}{ point 3} & Group A & $0.11 \pm 0.02$ & $0.20 \pm 0.03$ & $0.33 \pm 0.04$ & $0.56 \pm 0.04$ & $0.67 \pm 0.05$ & $0.79 \pm 0.04$ & $0.93 \pm 0.03$ \\
\hline & & Group B & $0.09 \pm 0.02$ & $0.18 \pm 0.03$ & $0.31 \pm 0.03$ & $0.49 \pm 0.05$ & $0.63 \pm 0.06$ & $0.74 \pm 0.07$ & $0.87 \pm 0.05$ \\
\hline & & Group C & $0.11 \pm 0.03$ & $0.22 \pm 0.03$ & $0.41 \pm 0.02$ & $0.64 \pm 0.09$ & $0.80 \pm 0.11$ & $1.02 \pm 0.13$ & $1.35 \pm 0.07$ \\
\hline
\end{tabular}



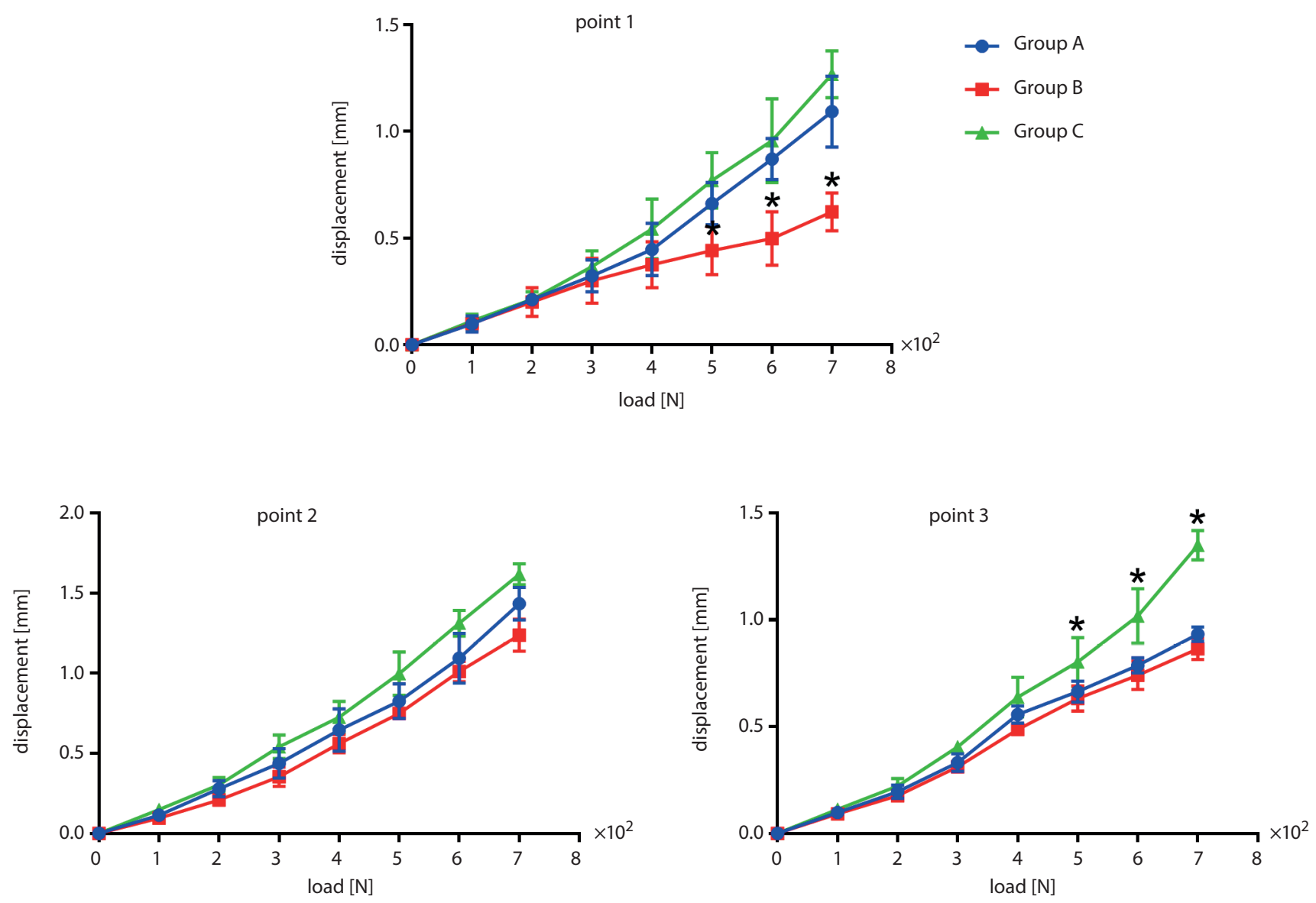

Fig. 6. Relationship between the displacement of the fracture line and the load force of the 3 points ${ }^{*} p<0.05$.

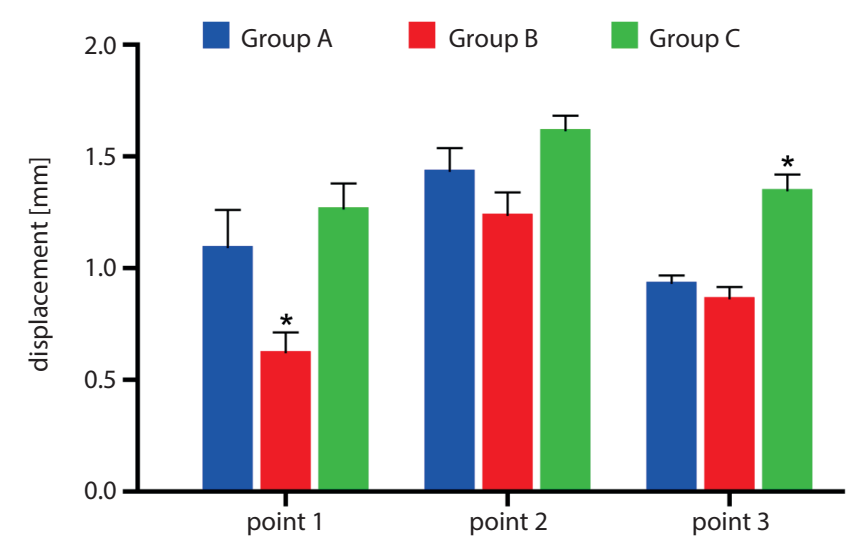

Fig. 7. Mean displacement for 3 groups in each point when the load force reached $700 \mathrm{~N}$

${ }^{*} p<0.05$.

$168.4830 \pm 14.8091 \mathrm{~N} / \mathrm{mm}$ and $83.1300 \pm 3.8091 \mathrm{~N} / \mathrm{mm}$, respectively (Table 2). Group B was significantly stiffer than Groups A and C $(\mathrm{p}<0.05)$ (Table 3).

\section{Loads at failure of internal fixation}

The dislocation of the articular surface fracture $>3 \mathrm{~mm}$ was recognized as the internal fixation failure standard.7,20
Table 2. Mean stiffness values and standard deviations for different fixation modalities at a load of $700 \mathrm{~N}$

\begin{tabular}{|l|c|c|c|}
\multirow{2}{*}{ Groups } & \multirow{2}{*}{$\mathrm{n}$} & \multicolumn{2}{|c|}{ Stiffness [N/mm] } \\
\cline { 3 - 4 } & & mean \pm SD & $95 \% \mathrm{Cl}$ \\
\hline Group A & 6 & $122.4800 \pm 8.8480$ & $113.1946,131.7654$ \\
\hline Group B & 6 & $468.4830 \pm 14.8091$ & $152.8771,183.9595$ \\
\hline Group C & 6 & $83.1300 \pm 3.8091$ & $79.1326,87.1274$ \\
\hline
\end{tabular}

$\mathrm{n}$ - number of specimens; SD - standard deviation; $95 \% \mathrm{Cl}$ - 95\% confidence interval; Group A - iliosciatic plates; Group B - 3D printing acetabular-wing plates; Group C - 2 parallel reconstruction plates.

The stability of the internal fixation is reflected by the load at which failure occurs. These values were $1378.83 \pm 34.383 \mathrm{~N}$, $1516.83 \pm 30.896 \mathrm{~N}$ and $1351.00 \pm 26.046 \mathrm{~N}$ for Groups A, B and $C$, respectively (Table 4). Group B was significantly superior to Groups A and C ( $<0.05)$. No significant differences were evident between Groups A and C (p > 0.05) (Table 5).

\section{Discussion}

Acetabular fractures are one of the most difficult fractures to treat due to their complex anatomical structures, morphological differences among individuals and 
Table 3. Comparisons of axial stiffness. The Group B constructs were stiffer than the Group A and Group C constructs ( $p<0.05$, $a=0.05$ ). Multiple comparisons

\begin{tabular}{|c|c|c|c|c|c|c|c|}
\hline \multicolumn{8}{|c|}{ Dependent variable: Axial stiffness } \\
\hline & \multirow{2}{*}{\multicolumn{2}{|c|}{ Group }} & \multirow{2}{*}{ mean difference } & \multirow{2}{*}{ SE } & \multirow{2}{*}{$\mathrm{p}$-value } & \multicolumn{2}{|c|}{$95 \% \mathrm{Cl}$} \\
\hline & & & & & & lower bound & upper bound \\
\hline \multirow{6}{*}{ LSD } & \multirow{2}{*}{ Group A } & Group B & -45.93833 & 5.88883 & 0.000 & -58.4901 & -33.3866 \\
\hline & & Group C & 39.35000 & 5.88883 & 0.000 & 26.7983 & 51.9017 \\
\hline & \multirow{2}{*}{ Group B } & Group A & 45.93833 & 5.88883 & 0.000 & 33.3866 & 58.4901 \\
\hline & & Group C & 85.28833 & 5.88883 & 0.000 & 72.7366 & 97.8401 \\
\hline & \multirow{2}{*}{ Group C } & Group A & -39.35000 & 5.88883 & 0.000 & -51.9017 & -26.7983 \\
\hline & & Group B & -85.28833 & 5.88883 & 0.000 & -97.8401 & -72.7366 \\
\hline \multirow{6}{*}{ Dunnett T3 } & \multirow{2}{*}{ Group A } & Group B & -45.93833 & 7.04268 & 0.000 & -66.6754 & -25.2013 \\
\hline & & Group C & 39.35000 & 3.93268 & 0.000 & 27.2371 & 51.4629 \\
\hline & \multirow{2}{*}{ Group B } & Group A & 45.93833 & 7.04268 & 0.000 & 25.2013 & 66.6754 \\
\hline & & Group C & 85.28833 & 6.24258 & 0.000 & 64.9809 & 105.5957 \\
\hline & \multirow{2}{*}{ Group C } & Group A & -39.35000 & 3.93268 & 0.000 & -51.4629 & -27.2371 \\
\hline & & Group B & -85.28833 & 6.24258 & 0.000 & -105.5957 & -64.989 \\
\hline
\end{tabular}

LSD - least significant difference; SE - standard error; 95\% Cl - 95\% confidence interval. The mean difference is significant at the 0.05 level.

Table 4. Failure test in cadaveric specimens used to compare 3 kinds of plate fixations: Compressive force

\begin{tabular}{|l|c|c|c|}
\multirow{2}{*}{ Groups } & \multirow{2}{*}{$\mathrm{n}$} & \multicolumn{2}{|c|}{ Compressive force [N] } \\
\cline { 3 - 4 } & & mean \pm SD & $95 \% \mathrm{Cl}$ \\
\hline Group A & 6 & $1378.83 \pm 34.383$ & $1342.75,1414.92$ \\
\hline Group B & 6 & $1516.83 \pm 30.896$ & $1484.41,1549.26$ \\
\hline Group C & 6 & $1351.00 \pm 26.046$ & $1323.67,1378.33$ \\
\hline
\end{tabular}

SD - standard deviation; 95\% Cl - 95\% confidence interval.

limitations of surgical approaches. In addition, it is difficult to fix them because of the thinness of quadrilateral plate and bearing area. Pelvic malunion and joint incoordination are associated with the long-term risk of osteoarthritis, and the greatest challenge in the management of acetabular fractures is to obtain adequate fracture reduction. ${ }^{21-23}$ The ultimate goal of complex acetabular fractures therapy is to reduce complications, improve quality of life, and maximize recovery and post-recovery functional status. It has remained a great challenge to find an effective way to fix a quadrilateral plate for complex acetabular fractures. As is known to all, it is difficult to achieve anatomical contouring intraoperatively due to the complexity of the acetabulum, so surgeons need to pre-contour the conventional reconstruction plate when using it during the operations. ${ }^{14}$ However, the repeated bending of the plate will cause

Table 5. Comparisons of compressive force for different fixations. Multiple comparisons

\begin{tabular}{|c|c|c|c|c|c|c|c|}
\hline \multicolumn{8}{|c|}{ Dependent variable: Compressive force } \\
\hline & \multirow{2}{*}{\multicolumn{2}{|c|}{ Group }} & \multirow{2}{*}{ mean difference } & \multirow{2}{*}{ SE } & \multirow{2}{*}{$\mathrm{p}$-value } & \multicolumn{2}{|c|}{$95 \% \mathrm{Cl}$} \\
\hline & & & & & & lower bound & upper bound \\
\hline \multirow{6}{*}{ LSD } & \multirow{2}{*}{ Group A } & Group B & $-138.000^{*}$ & 17.686 & 0.000 & -175.70 & -100.30 \\
\hline & & Group C & 27.833 & 17.686 & 0.136 & -9.86 & 65.53 \\
\hline & \multirow{2}{*}{ Group B } & Group A & $138.000^{*}$ & 17.686 & 0.000 & 100.30 & 175.70 \\
\hline & & Group C & $165.833^{*}$ & 17.686 & 0.000 & 128.14 & 203.53 \\
\hline & \multirow{2}{*}{ Group C } & Group A & -27.833 & 17.686 & 0.136 & -65.53 & 9.86 \\
\hline & & Group B & $-165.833^{*}$ & 17.686 & 0.000 & -203.53 & -128.14 \\
\hline \multirow{6}{*}{ Dunnett T3 } & \multirow{2}{*}{ Group A } & Group B & $-138.000^{*}$ & 18.871 & 0.000 & -191.49 & -84.51 \\
\hline & & Group C & 27.833 & 17.609 & 0.358 & -22.63 & 78.30 \\
\hline & \multirow{2}{*}{ Group B } & Group A & $138.000^{*}$ & 18.871 & 0.000 & 84.51 & 191.49 \\
\hline & & Group C & $165.833^{*}$ & 16.497 & 0.000 & 118.93 & 212.74 \\
\hline & \multirow{2}{*}{ Group C } & Group A & -27.833 & 17.609 & 0.358 & -78.30 & 22.63 \\
\hline & & Group B & $-165.833^{*}$ & 16.497 & 0.000 & -212.74 & -118.93 \\
\hline
\end{tabular}

The mean difference is significant at the 0.05 level. 
fatigue damage and lead to complications of internal fixation failure. In recent years, one possible way to solve this problem is using 3D printing technology to design and assemble anatomical models. Here, we have designed a novel customized wing-shaped plate for the particular acetabulum rupture according to the mirror model of the patient's healthy side of the hemi-pelvis. The customized fixation system designed directly from the specific patient is better adapted to the bone surface when compared with the traditional fixation system, which will reduce the time of bending and fixing the plate during the operation. It contains 3 parts, of which the anterior branch was to be fixed to the pubic branch, the posterior was to be fixed to the above great sciatic notch, and the lower branch was to be fixed to the ischium spine. The lower 2 parts form an arc as a barrier plate on the surface that can effectively fix the quadrilateral area of the comminuted fracture, avoiding medial subluxation of the femoral head. This design concept was consistent with the direction of the acetabular trabecula and can effectively fix the anterior and posterior column of the acetabulum. A personalized bone plate can facilitate better preoperative planning and better intraoperative work. It could greatly reduce the operation time and blood loss during surgery with no need for pre-bending according of the acetabulum surface. And in previous studies, we have demonstrated that the customized acetabular-wing plates had the equivalent hardness, tensile strength, yield strength, and mechanical properties as traditional plates. ${ }^{18}$

Quadrilateral surface buttress plates and traditional forms of both column acetabular fracture fixation usually use multiple bone plates during the operation. In this study, we used just 1 plate and fewer screws instead of multiple reconstruction plates to fix the ruptured pelvis, which could decrease the risk of the screws penetrating the acetabulum fossa. Besides, the results presented that a single wing-plate is stable enough, as the axial stiffness of Groups A, B and C were $122.4800 \pm 8.8480 \mathrm{~N} / \mathrm{mm}, 168.4830 \pm 14.8091 \mathrm{~N} / \mathrm{mm}$ and $83.1300 \pm 3.8091 \mathrm{~N} / \mathrm{mm}$, respectively (Table 2 ). Group B was significantly stiffer than Groups A and C (p < 0.05) (Table 3). The novel customized wing-shape plates spanning the posterior and anterior columns are biomechanically comparable and, in some cases, superior to traditional forms of fixation in this cadaveric hemipelvis model. Another advantage is that fracture reduction could be judged according to the surface morphology of the bone plate during the operation, thus avoiding errors caused by intraoperative fluoroscopy.

Computer-aided design (CAD) combined with 3D printing is a novel surgical technique that is frequently applied in the orthopedic field. ${ }^{18,24,25}$ Computer-aided design and $3 \mathrm{D}$ printing technology have been used for the design and assembly of anatomical models, the production of surgery assisted instruments and the printing of implants and prostheses. ${ }^{26-28}$ The procedure is typically conducted for preoperative bending of the bone plates to assess the position and length of the screws using a 3D printing pelvic model. Patient-specific pre-contoured plates in acetabular fracture have been studied by a few researchers, and metal 3D printing technology has been widely used to fabricate customized spinal prostheses, knee joint prostheses, and femoral prostheses, ${ }^{15}$ but personalized plate study was lacking. Selective laser welding (SLM) can be used to rapidly prepare customized plates to meet the urgent need of surgical treatment. Using 3D printers as production tools has become known in the industry as additive manufacturing (as opposed to the old, subtractive business of cutting, drilling and bashing metal). Therefore, combined with SLM, a customized plate for complex acetabular fracture fixation can be used in clinics to improve the quality and efficiency of surgery.

Anterior columns can be combined to posterior hemitransverse fractures (ACPHTFs), which commonly occur in geriatric acetabular fractures. ${ }^{29}$ To assess the stability of anterior columns, posterior columns and quadrilateral plates, we designed complex acetabular fractures on the basis of ACPHTFs and added an additional fracture line across the acetabular dome to the iliosciatic notch, parallel to the posterior fracture line. This fracture model splits the quadrilateral plate into 2 distinct regions, with the rear region and the acetabulum being weight-bearing free, thus fitting our experimental aims. Meanwhile, the complex classical fracture model offers complex acetabulum fracture references for acetabulum biomechanical research. To assess the direct blocking effect of the steel plate on the quadrilateral plate and acetabular dome, we made some artificial upper femur sections. The artificial femoral head was oriented $25^{\circ}$ in the retroversion and $45^{\circ}$ in the abduction as shown by Khajavi et al. ${ }^{30}$ Theoretically, the force applied to acetabular fossa from a single stance was equal to the double Body Weight (BW). However, patients were recommended to limit weight-bearing loads to about $20 \%$ of their BW during recovery and after surgery. ${ }^{31,32}$ In this study, we selected a rigorous loading scenario (up to $700 \mathrm{~N}$ ) to simulate the body bearing. Force and displacement data was collected and analyzed to calculate the construction stiffness.

The standard of the "internal fixation failure" was a 3-mm acetabular fracture gap, which easily leads to arthritis. ${ }^{4,7,20}$ In the failure test, we monitored the increase in fracture gap to $3 \mathrm{~mm}$ in the presence of a loading force, incrementally increased at $20 \mathrm{~N} / \mathrm{s}$. Control groups consisted of intrapelvic buttressing fixation as a method to support the quadrilateral plate. A single group produced an intrapelvic buttressing plate along the arcuate, in combination with an additional pelvic plate and lag screws to fix the anterior and posterior columns. The other group had intrapelvic buttressing from the iliac surface to the sitting joint, and could prevent quadrilateral plate medial displacement and fix the posterior column.

There were limitations to this study. Firstly, we chose to use a fresh frozen cadaver pelvis, with a sample size 
of 6 for each group. Although bone mineral density was quantified before the biomechanical test, the accuracy of the experiment may have been affected by the insufficient samples and different specimen quality levels. Cadaveric specimens were from an older population and there were individual differences among them. Secondly, our experiments focused on mechanical studies of the immediate stability of fracture repair and did not simulate a gait loading condition. It is believed that the early stages of healing involving static loading allow for a comparison of the biomechanical properties of implants, and immediate biomechanical stability has an important influence on fracture healing during this period. Thirdly, we excised strong musculature that leads to deforming forces, providing only weak support for the fractures. There are, therefore, deficiencies that require improvement. These include: 1) customized 3D printing acetabular-wing plates designed on the basis of the anatomic reduction of fractures, and if fracture reduction does not occur, the bone surface becomes poorly fitted to the bone plate, and pre-set screws become difficult to position; 2) during the design and production processes, the influence of local soft tissue was not fully considered. The internal fixation method based on the preoperative design may thus not be realized by the soft tissue influence. Therefore, the outcome of wing-plate for acetabular fracture requires long-term follow-up in clinical practice.

\section{Conclusions}

The main finding of this study was that treatment of displaced both-column acetabular fractures using a 3D printing wing-plate appears to be a safe option with good stability outcomes. Our method used computer aid design according to the digital pelvic model, to which patientspecific implants were perfectly matched to the ruptured acetabulum. Combined with 3D printing technology, the customized plate with optimal structure can be produced quickly to meet the emergency time requirements.

\section{ORCID iDs}

Xiangyuan Wen (1) https://orcid.org/0000-0001-9939-4967

Hai Huang (10) https://orcid.org/0000-0003-0289-9825

Canbin Wang (1) https://orcid.org/0000-0002-1911-5065

Jianghui Dong (1) https://orcid.org/0000-0003-3961-1688

Xuezhi Lin (1) https://orcid.org/0000-0003-1362-515X

Fuming Huang (1) https://orcid.org/0000-0002-2036-1626

Hua Wang (1) https://orcid.org/0000-0001-9004-176X

Liping Wang (1) https://orcid.org/0000-0001-9355-1167

Shicai Fan (1) https://orcid.org/0000-0002-1993-6074

\section{References}

1. Tile M. Pelvic ring fractures: Should they be fixed? J Bone Joint Surg Br. 1988;70(1):1-12.

2. Peter RE. Open reduction and internal fixation of osteoporotic acetabular fractures through the ilio-inguinal approach: Use of buttress plates to control medial displacement of the quadrilateral surface. Injury. 2015;46(Suppl 1)S2-S7.
3. Wu XB, Wang JQ, Sun X, Zhao CP. Guidance for treatment of pelvic acetabular injuries with precise minimally invasive internal fixation based on the orthopaedic surgery robot positioning system. Orthop Surg. 2019;11(3):341-347.

4. Laflamme GY, Hebert-Davies J, Rouleau D, Benoit B, Leduc S. Internal fixation of osteopenic acetabular fractures involving the quadrilateral plate. Injury. 2011;42(10):1130-1134.

5. Culemann U, Holstein JH, Kohler D, et al. Different stabilisation techniques for typical acetabular fractures in the elderly - a biomechanical assessment. Injury. 2010;41(4):405-410.

6. Butterwick D, Papp S, Gofton W, Liew A, Beaule PE. Acetabular fractures in the elderly: Evaluation and management. J Bone Joint Surg Am. 2015;97(9):758-768.

7. Boelch SP, Jordan MC, Meffert RH, Jansen H. Comparison of open reduction and internal fixation and primary total hip replacement for osteoporotic acetabular fractures: A retrospective clinical study. Int Orthop. 2017;41(9):1831-1837.

8. Letournel E. Acetabulum fractures: Classification and management. Clin Orthop Relat Res. 1980(151):81-106.

9. White G, Kanakaris NK, Faour O, Valverde JA, Martin MA, Giannoudis PV. Quadrilateral plate fractures of the acetabulum: An update. Injury. 2013;44(2):159-167.

10. Sen RK, Tripathy SK, Aggarwal S, Goyal T, Mahapatra SK. Comminuted quadrilateral plate fracture fixation through the iliofemoral approach. Injury. 2013;44(2):266-273.

11. Russell GV Jr., Nork SE, Chip Routt ML Jr. Perioperative complications associated with operative treatment of acetabular fractures. JTrauma. 2001;51(6):1098-1103.

12. Bott A, Odutola A, Halliday R, Acharya MR, Ward A, Chesser TJS. Long-term patient-reported functional outcome of polytraumatized patients with operatively treated pelvic fractures. J Orthop Trauma. 2019;33(2):64-70.

13. Mehin R, Jones B, Zhu Q, Broekhuyse H. A biomechanical study of conventional acetabular internal fracture fixation versus locking plate fixation. Can J Surg. 2009;52(3):221-228.

14. Maini L, Sharma A, Jha S, Sharma A, Tiwari A. Three-dimensional printing and patient-specific pre-contoured plate: Future of acetabulum fracture fixation? Eur J Trauma Emerg Surg. 2018;44(2):215-224.

15. Malik HH, Darwood AR, Shaunak S, et al. Three-dimensional printing in surgery: A review of current surgical applications. J Surg Res. 2015;199(2):512-522.

16. Fang $\mathrm{C}$, Cai $\mathrm{H}$, Kuong $\mathrm{E}$, et al. Surgical applications of three-dimensional printing in the pelvis and acetabulum: From models and tools to implants. Unfallchirurg. 2019;122(4):278-285.

17. Letournel E. Fractures of the acetabulum: A study of a series of 75 cases - Les fractures du cotyle, etude d'une serie de 75 cas.J Je Chirurgie. 1961; 82:47-87 [translated and substantially abridged]. J Orthop Trauma. 2006;20(1 Suppl):S15-S19.

18. Wang D, Wang Y, Wu S, et al. Customized a Ti6Al4V bone plate for complex pelvic fracture by selective laser melting. Materials (Basel). 2017;10(1):35.

19. Gillispie GJ, Babcock SN, McNamara KP, et al. Biomechanical comparison of intrapelvic and extrapelvic fixation for acetabular fractures involving the quadrilateral plate. J Orthop Trauma. 2017;31(11): 570-576.

20. Barnes SN, Stewart MJ. Central fractures of the acetabulum: A critical analysis and review of literature. Clin Orthop Relat Res. 1976;(114):276-281.

21. Matta JM. Fractures of the acetabulum: Accuracy of reduction and clinical results in patients managed operatively within three weeks after the injury. J Bone Joint Surg Am. 1996;78(11):1632-1645.

22. Mears DC, Velyvis JH, Chang CP. Displaced acetabular fractures managed operatively: Indicators of outcome. Clin Orthop Relat Res. 2003; (407):173-186.

23. Ziran N, Soles GLS, Matta JM. Outcomes after surgical treatment of acetabular fractures: A review. Patient Saf Surg. 2019;13:16. doi: 10.1186/s13037-019-0196-2

24. Boudissa M, Courvoisier A, Chabanas M, Tonetti J. Computer assisted surgery in preoperative planning of acetabular fracture surgery: State of the art. Expert Rev Med Devices. 2018;15(1):81-89.

25. Cromeens BP, Ray WC, Hoehne B, Abayneh F, Adler B, Besner GE. Facilitating surgeon understanding of complex anatomy using a threedimensional printed model. J Surg Res. 2017;216:18-25. 
26. Aimar A, Palermo A, Innocenti B. The role of 3D printing in medical applications: A state of the art. J Healthc Eng. 2019;2019:5340616.

27. Wan L, Zhang X, Zhang S, et al. Clinical feasibility and application value of computer virtual reduction combined with 3D printing technique in complex acetabular fractures. Exp Ther Med. 2019;17(5): 3630-3636.

28. Weidert S, Andress S, Suero E, et al. 3D printing in orthopedic and trauma surgery education and training: Possibilities and fields of application [in German]. Unfallchirurg. 2019;122(6):444-451. doi:10. 1007/s00113-019-0650-8
29. Karim MA, Abdelazeem AH, Youness M, El Nahal WA. Fixation of quadrilateral plate fractures of the acetabulum using the buttress screw: A novel technique. Injury. 2017:48(8):1813-1818.

30. Khajavi K, Lee AT, Lindsey DP, Leucht P, Bellino MJ, Giori NJ. Single column locking plate fixation is inadequate in two column acetabular fractures. A biomechanical analysis. J Orthop Surg Res. 2010;5:30.

31. Ryken TC, Owen BD, Christensen GE, Reinhardt JM. Image-based drill templates for cervical pedicle screw placement. J Neurosurg Spine. 2009;10(1):21-26.

32. Ma T, Xu YQ, Cheng YB, et al. A novel computer-assisted drill guide template for thoracic pedicle screw placement: A cadaveric study. Arch Orthop Trauma Surg. 2012;132(1):65-72. 